\title{
Functional Anatomy of Incisal Biting in Aplodontia rufa and Sciuromorph Rodents - Part 2: Sciuromorphy Is Efficacious for Production of Force at the Incisors
}

\author{
Robert E. Druzinsky \\ Departments of Occupational and Physical Therapy, Governors State University, University Park, III., USA
}

\section{Key Words}

Masticatory apparatus $\cdot$ Evolution $\cdot$ Rodent $\cdot$ Sciuromorph •

Protrogomorph

\begin{abstract}
The protrogomorph condition of the rodent masticatory apparatus is thought to be present in only one living species, the mountain beaver Aplodontia rufa. The major anatomical difference between protrogomorphs and sciuromorphs is that the relative size of one part of the masseter muscle, the anterior lateral masseter, is much greater in sciuromorphs than in protrogomorphs. The mechanics of force production at the incisors were compared in A. rufa and six sciuromorph rodents. Is the sciuroid masticatory apparatus more effective for production of forces at the incisors during biting than the primitive, protrogomorph condition? To answer this question, three measures of mechanical ability were employed and three hypotheses were tested: (1) the mechanical advantage of the adductor musculature is greater in sciuromorphs than in A. rufa; (2) the relative force produced at the incisors is greater in sciuromorphs than in A. rufa, and (3) the relative amount of force produced that can be used to drive the incisors into an object, is greater in sciuromorphs than in A. rufa. The results demonstrated that the protrogomorph, A. rufa, is not as efficient at generating bite forces at the incisors as the sciuromorphs.

Copyright $\odot 2010$ S. Karger AG, Basel
\end{abstract}

In his seminal paper on grades and clades of rodents, Wood [1965] argued that the sciuromorph, hystricomorph, and myomorph grades represent modifications of the primitive protrogomorph condition that are adaptations for increased efficiency of the incisors. But since its publication little work has been done to test his hypothesis. Satoh [1997, 1998] and Satoh and Iwaku [2004,

\section{Abbreviations used in this paper}

\section{ALM}

AZM

CMJ

$\mathrm{IO}$

MA

PCS

PI

PLM

PM

PZM

SM

$\mathrm{T}$

TA

TP

TZ

$\mathrm{ZM}$

\author{
Anterior lateral masseter \\ Anterior zygomaticomandibularis \\ Craniomandibular joint \\ Incisal occlusion \\ Moment arm \\ Physiological cross-section \\ Internal pterygoid \\ Posterior lateral masseter \\ Posterior masseter \\ Posterior zygomaticomandibularis \\ Superficial masseter \\ Temporalis \\ Anterior temporalis \\ Posterior temporalis \\ Suprazygomatic portion of the temporalis \\ Zygomaticomandibularis
}

\section{KARGER}

() 2010 S. Karger AG, Basel

Fax +4161306 1234

E-Mail karger@karger.ch

www.karger.com
Accessible online at: www.karger.com/cto
Robert E. Druzinsky

Departments of Occupational and Physical Therapy

Governors State University

1 University Parkway, University Park, IL 60484 (USA)

Tel. +1 708235 2147, Fax +1 708534 1647, E-Mail r-druzinsky@govst.edu 
2006, 2008] have studied the mechanics of force production at the incisors in several myomorphs and conclude that the anterior masseter muscle fibers are capable of producing large forces at the incisors. Ball and Roth's [1995] and Velhagen and Roth's [1997] comparative studies of the masticatory apparatus in squirrels (and outgroups, including Aplodontia) do not provide a mechanical analysis of incisal biting.

Morphometric analyses of the skull and mandible in marmots by Cardini [2003], Cardini and O'Higgins [2004] and Cardini et al. [2005] provide interesting insights into phylogenetic patterns of shape changes but no evidence for increased ability to produce forces at the incisors. Cardini and Tongiorgi [2003] studied shape changes in the mandible of Marmotaflaviventris during growth and development. Their results suggest that as these animals mature, the size (based on attachment area) and the mechanical efficiency of the anterior lateral masseter (ALM) increase dramatically, so that there is a significant allometric increase in the ability to produce biting force at the incisors during ontogeny. Thorington and Darrow [1996] compared the jaw muscles of squirrels (also including Aplodontia as an outgroup). Their mechanical analysis is limited to lever arm/load arm ratios for the mandibular attachment areas of the major masticatory muscles, the load arm being the length from the tip of the mandibular incisor to the condyle. While the ratios tend to be low in Aplodontia, the results do not show a clear improvement in the ability of sciuromorphs to produce forces at the incisors when compared to the protrogomorph Aplodontia.

Today, in spite of lingering questions with regard to the phylogenetics of protrogomorphs [see Druzinsky, 2010, companion paper], there does appear to be a consensus that (1) the protrogomorph condition of the masticatory muscles is the primitive condition for the Rodentia [Wood, 1937, 1965], that (2) Aplodontia rufa is the only extant protrogomorph rodent, and that (3) sciuromorph, hystricomorph and myomorph arrangements of the masticatory muscles are, in some way, mechanical 'improvements' over the primitive, protrogomorph, condition.

In the analysis of the mechanics of incisal biting that follows, A. rufa is used to represent the protrogomorph condition of the masticatory apparatus and compared to 5 sciuroids (Marmota monax, Tamias minimus, Ratufa affinis, Sciurus variagatoides, Cynomys ludovicianus) and one nonsciuroid sciuromorph (Thomomys talpoides). The major anatomical difference between protrogomorphs and sciuromorphs is that the relative size of one part of the masseter muscle, the ALM, is larger in sciuromorphs than in protrogomorphs. Is the sciuroid masticatory apparatus more effective for production of forces at the incisors during biting than the primitive, protrogomorph condition?

To answer this question, three measures of mechanical ability were employed and three hypotheses were tested: (1) the mechanical advantage of the adductor musculature, as measured by the length of the MA of the resultant of adductor forces as a percentage of jaw length, is greater in sciuromorphs than in A. rufa;

(2) the relative force produced at the incisors, as measured by the bite force at the incisors as a percentage of the total force produced by the adductor muscles, is greater in sciuromorphs than in A. rufa, and

(3) the relative amount of force produced that can be used to drive the incisors into an object, as measured by the bite force projected along the long axis of the incisor as a percentage of total bite force, is greater in sciuromorphs than in A. rufa.

These three measures of mechanical ability are not independent of one another, but each measures a different feature of the mechanics of biting. No single measure of the effectiveness of biting should be relied upon since comparisons of different mechanical measures may yield different results [e.g. Stern, 1974; Gans and De Vree, 1987].

\section{Materials and Methods}

Five woodchucks (M. monax) and eight mountain beavers ( $A$. rufa) obtained for the study [Druzinsky, 1989, 1995, 2010] were dissected. Single specimens from 5 sciuromorphous species, from the collections of the Field Museum of Natural History, Chicago, were also dissected [Druzinsky, 2010, table 1]. Skulls and mandibles of each species dissected were studied from the collections of the Department of Oral Anatomy, the FMNH, and the Division of Mammals, American Museum of Natural History, New York [Druzinsky, 2010, table 1].

\section{Physiological Cross-Sections}

Ten fasciculi were measured for each muscle with a dissecting microscope, and the average length of the fasciculi was used to calculate the physiological cross-sections (PCSs) for each muscle. Fasciculi rather than fibers were measured in the present study since fasciculi are much easier to dissect and provide good estimates of fiber lengths, assuming that the fibers in a muscle are not serially connected [normally a reasonable assumption, but see English, 1985]. There was no indication of serially connected fasciculi in these muscles, but histological staining of the muscles has not been undertaken. Calculations of the PCSs are presented in appendix 1 . 


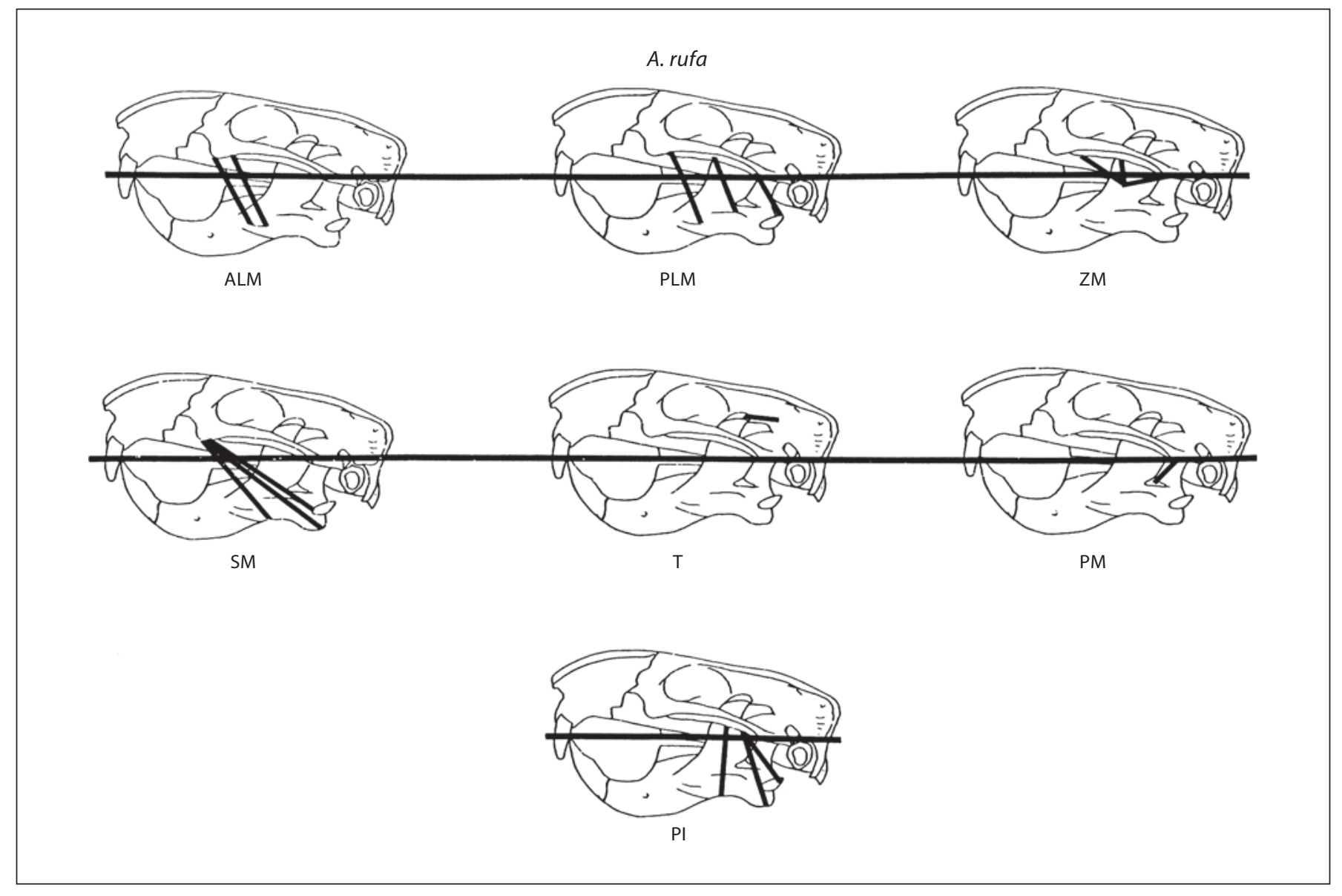

Fig. 1. Representative fibers used to estimate the line of action of each of seven adductor muscles in $A$. rufa.

Coordinate System and Line of Action

The line of action and magnitude of force was estimated for each of seven adductor muscles in two jaw positions for each osteological specimen. A modified version of the 'central fiber' method [Mainland and Hiltz, 1934; Hiiemae, 1971; Bekele, 1983] was employed. In the 'central fiber' method, the force produced by a muscle is conceived as acting along a line between the center of the attachment at the origin and the center of attachment at the insertion.

Rather than estimating the center of origin and center of insertion for each muscle, for some of the muscles, the line of action was obtained by estimating lines of action for representative fibers of the muscle (fig. 1,2) and then performing a vector addition to find the line of action of the whole muscle. The magnitudes of the vectors were determined by dividing the force produced by each muscle (as estimated using the PCSs, see below) equally between the fibers. $\mathrm{X}, \mathrm{Y}$, and $\mathrm{Z}$ coordinates of each end of the representative fibers defined above from the right side of each skull were recorded. The origin of the coordinate system is the superior end of the mandibular condyle in the right glenoid fossa (fig. 3). The horizontal axis was defined as a line passing between the origin and the superior end of the occlusal wear facet on the right upper incisor, which represents the superior limit of movement of the lower incisor, or $0^{\circ}$ gape.

The skulls were mounted in a stereotaxic apparatus [Hiiemae, 1971; Druzinsky, 1981; Bekele, 1983] at two gapes: (1) the beginning of incisal occlusion (IO) at which the tips of the upper and lower incisors pass each other (roughly $6-8^{\circ}$ gape), and (2) $30^{\circ}$ gape, which represents the beginning of a large bite.

\section{Assumptions}

Any intraspecific comparison of mechanics requires that the conditions are similar in all of the species studied. In the present study, the following conditions were assumed:

(1) bilaterally symmetrical muscle activity;

(2) simple rotation around the mandibular condyle between IO and $30^{\circ}$ gape, and

(3) all of the jaw adductors are active at maximum force.

Study of incisal biting in live A. rufa and M. monax [Druzinsky, 1989, 1995] demonstrates that biting is essentially a behavior that occurs along the midline with bilaterally symmetrical muscle activity, and that during powerful biting all of the adductor mus- 

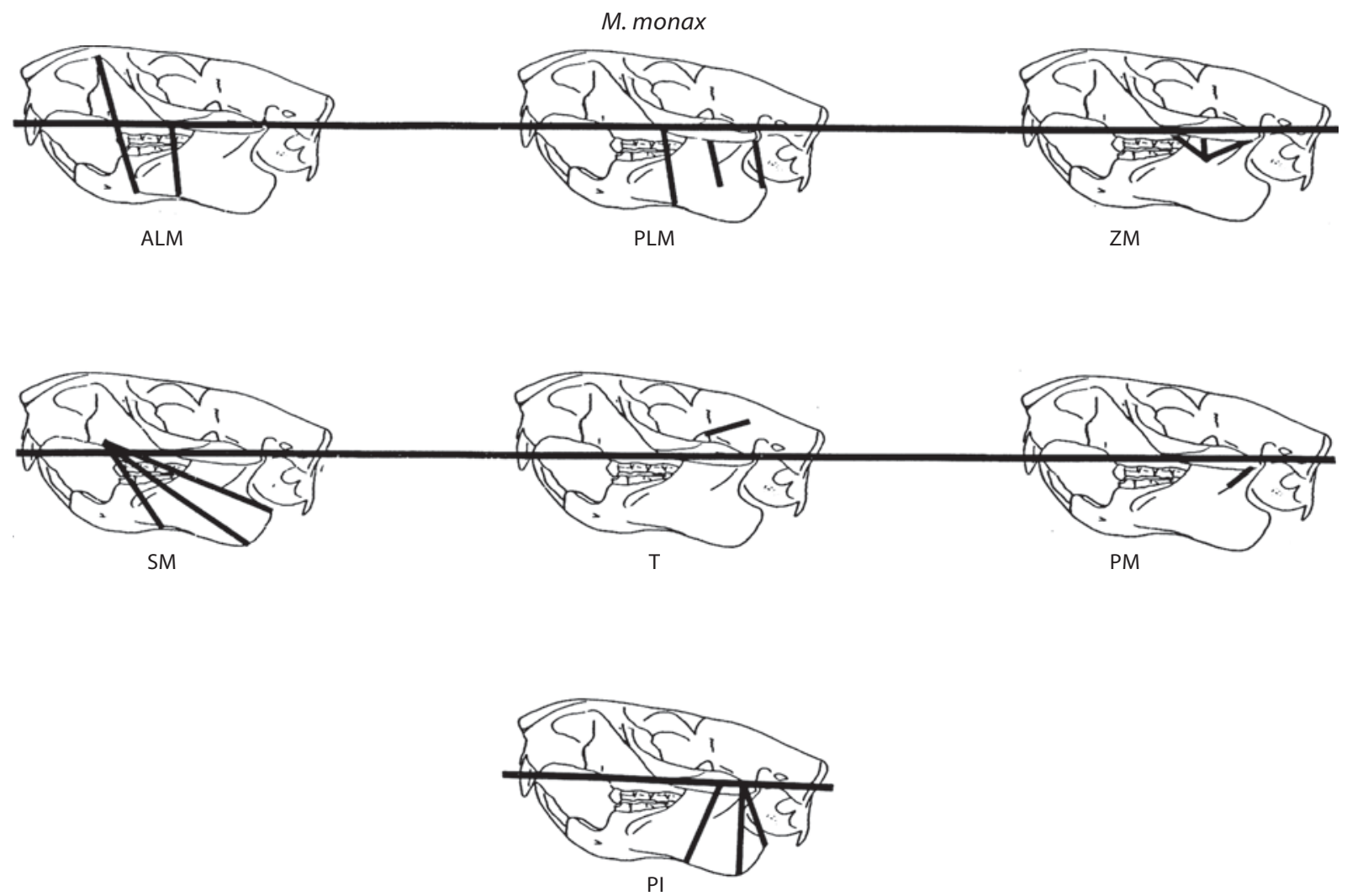

Fig. 2. Representative fibers used to estimate the line of action of each of seven adductor muscles in M. monax.

cles are active. Therefore, mechanical analyses utilizing a midline projection that assumes bilaterally symmetrical muscle activity, and estimation of muscular forces from PCSs (an estimate of maximum tetanic tension), should provide reasonable estimates of forces produced during powerful incisal biting. Biting frequently begins at gapes of $30^{\circ}$ or more. Therefore, forces produced at IO are compared to forces produced at a gape of $30^{\circ}$. During biting, the condyles translate anteriorly in the glenoid fossa and the jaw rotates open from this anterior position. Although incisal biting has been studied only in A. rufa and M. monax, it is assumed that the mechanics of biting are similar in all of the species considered. There are no features of the masticatory apparatus of any of these species that would suggest that these assumptions are not reasonable.

Any estimate of force based on a PCS is an estimate based on the maximum tetanic tension produced by that muscle. Thus, the present study compares the species at maximum biting force.

\section{Projection}

The system is studied in a two-dimensional, lateral projection since incisal biting is an activity that occurs primarily along the midline. Bilaterally symmetrical activity of the adductor muscles is assumed. The magnitudes of the forces produced by the adductor muscles are estimated by determining the PCS for each muscle.

\section{Mechanics}

Mechanical calculations are presented in detail in appendix 1.

\section{Statistics}

Since the sample sizes were small, nonparametric statistics were employed for most tests because they do not require the assumption that the samples are normally distributed. The KruskalWallis one-way analysis of variance by ranks was used to test for differences among the seven species compared in the mechanical analysis [Siegel, 1956]. Statistical calculations were performed on a microcomputer using the SYSTAT statistical software package. 


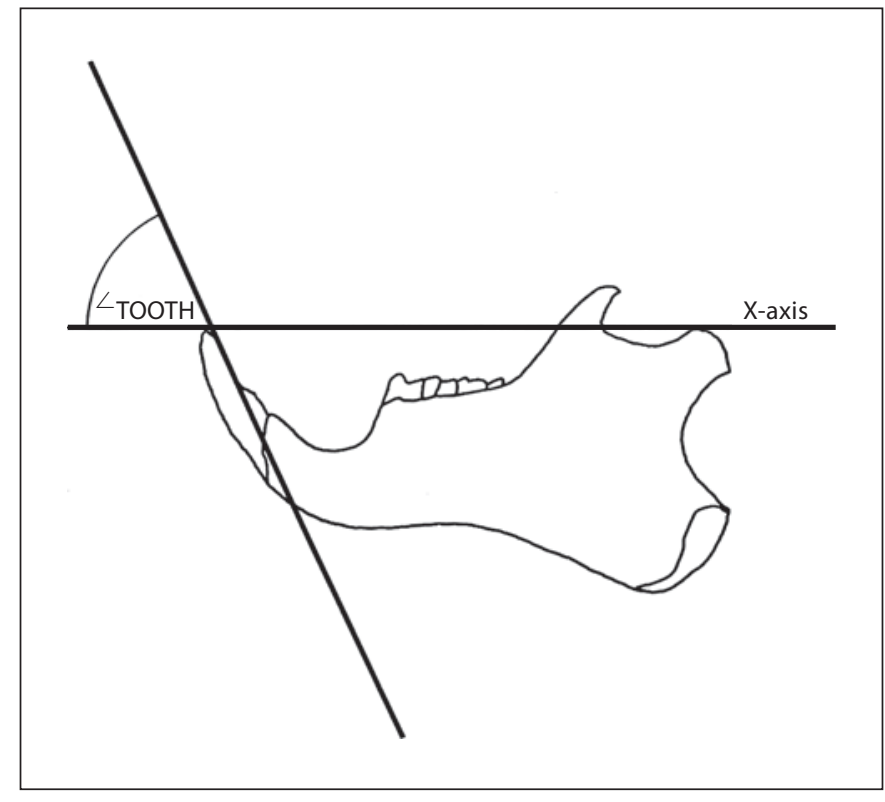

Fig. 3. The long axis of the lower incisor makes an angle $\left({ }^{\circ}\right.$ TоОтн $)$ with the horizontal axis at IO.

\section{Results}

\section{Mechanics}

PCSs and estimated forces produced by the adductor muscles are presented in table 1 . For most muscles, the percent contribution to the total PCS of the jaw adductors (or percentage of total force contributed by each individual muscle) is within a few percentage points of the contribution it makes to the total adductor mass. In some muscles, however, the difference is striking. In the masseter muscles, fascicle lengths tend to be relatively long, and contributions to the total PCS are slightly smaller than contributions to the total muscle mass.

The greatest differences between contributions to the total PCS and total adductor mass are found in the internal pterygoid (PI) because it is an extremely complex, multi-pinnate muscle with very short fasciculi in many of these species. The greatest increase is in Aplodontia, in which the PI contributes $8 \%$ of the total adductor mass, but $23 \%$ of the total PCS. In Thomomys and Sciurus, in which the PI is a fairly simple muscle, the contribution to the total PCS is within $1 \%$ of its contribution to the total adductor mass.

\section{Adductor Muscle Lines of Action}

Calculated lines of action of the adductor muscles are presented in figure 4 . The superficial masseter (SM) is the
Table 1. Adductor muscle masses, PCSs and forces produced by the adductor muscles

\begin{tabular}{|c|c|c|c|c|c|c|c|}
\hline \multirow[t]{2}{*}{ Species } & \multicolumn{7}{|c|}{ Muscle } \\
\hline & SM & ALM & PLM & $\mathrm{ZM}$ & PM & $\mathrm{T}$ & PI \\
\hline \multicolumn{8}{|l|}{ M. $\operatorname{monax}(\mathrm{n}=2)$} \\
\hline Mass, mean, $\mathrm{g}$ & 7.24 & 4.44 & 5.68 & 1.27 & 0.21 & 9.20 & 2.82 \\
\hline Mass, SD, g & 1.14 & 1.57 & 2.57 & 0.24 & 0.21 & 3.04 & 1.62 \\
\hline Mass, mean, \% & 24 & 14 & 18 & 4 & 1 & 30 & 9 \\
\hline Mass, SD, \% & 3 & 1 & 3 & 1 & 1 & 1 & 1 \\
\hline PCS, mean, $\mathrm{cm}^{2}$ & 4.17 & 2.25 & 4.48 & 1.04 & 0.15 & 5.27 & 5.05 \\
\hline PCS, SD, $\mathrm{cm}^{2}$ & 0.17 & 0.43 & 0.95 & 0.24 & 0.15 & 0.22 & 0.63 \\
\hline Force, mean, kg & 10.42 & 5.62 & 11.19 & 2.60 & 0.38 & 13.18 & 12.62 \\
\hline Force, mean, $\%$ & 19 & 10 & 20 & 5 & 1 & 24 & 23 \\
\hline Force, SD, \% & 2 & 1 & 3 & 1 & 1 & 3 & 1 \\
\hline \multicolumn{8}{|l|}{ A. $r u f a(n=4)$} \\
\hline Mass, mean, $\mathrm{g}$ & 1.78 & 0.60 & 2.67 & 0.92 & 0.23 & 3.64 & 0.84 \\
\hline Mass, SD, g & 0.20 & 0.19 & 0.61 & 0.18 & 0.09 & 0.83 & 0.11 \\
\hline Mass, mean, \% & 17 & 6 & 25 & 9 & 2 & 34 & 8 \\
\hline Mass, SD, \% & 1 & 2 & 2 & 2 & 1 & 4 & 2 \\
\hline PCS, mean, $\mathrm{cm}^{2}$ & 1.12 & 0.44 & 1.99 & 0.69 & 0.25 & 3.01 & 2.11 \\
\hline PCS, $\mathrm{SD}, \mathrm{cm}^{2}$ & 0.16 & 0.21 & 0.58 & 0.15 & 0.14 & 0.60 & 0.65 \\
\hline Force, mean, kg & 2.79 & 1.11 & 4.98 & 1.73 & 0.63 & 7.53 & 5.27 \\
\hline Force, mean, \% & 12 & 5 & 21 & 8 & 3 & 29 & 23 \\
\hline Force, SD, \% & 1 & 2 & 4 & 2 & 2 & 3 & 2 \\
\hline \multicolumn{8}{|l|}{ T. thomomys } \\
\hline Mass, mean, $\mathrm{g}$ & 0.08 & 0.34 & 0.11 & 0.02 & 0.02 & 0.20 & 0.04 \\
\hline Mass, mean, \% & 10 & 42 & 14 & 2 & 2 & 25 & 5 \\
\hline PCS, mean, $\mathrm{cm}^{2}$ & 0.10 & 0.44 & 0.24 & 0.05 & 0.05 & 0.41 & 0.09 \\
\hline Force, mean, kg & 0.26 & 1.11 & 0.59 & 0.12 & 0.13 & 1.02 & 0.22 \\
\hline Force, mean, \% & 7 & 32 & 17 & 4 & 4 & 30 & 6 \\
\hline \multicolumn{8}{|l|}{ R. affinis } \\
\hline Mass, mean, $\mathrm{g}$ & 1.41 & 1.55 & 1.06 & 0.04 & 0.04 & 1.69 & 0.61 \\
\hline Mass, mean, \% & 22 & 24 & 17 & 1 & 1 & 26 & 10 \\
\hline PCS, mean, $\mathrm{cm}^{2}$ & 1.39 & 1.45 & 1.11 & 0.05 & 0.06 & 1.76 & 1.61 \\
\hline Force, mean, kg & 3.47 & 3.64 & 2.77 & 0.11 & 0.16 & 4.40 & 4.03 \\
\hline Force, mean, \% & 19 & 20 & 15 & 1 & 1 & 24 & 22 \\
\hline \multicolumn{8}{|l|}{ S. variagatoides } \\
\hline Mass, mean, $\mathrm{g}$ & 0.04 & 0.06 & 0.05 & 0.01 & 0.01 & 0.06 & 0.03 \\
\hline Mass, mean, \% & 15 & 23 & 19 & 4 & 4 & 23 & 12 \\
\hline PCS, mean, $\mathrm{cm}^{2}$ & 0.04 & 0.07 & 0.06 & 0.03 & 0.01 & 0.07 & 0.04 \\
\hline Force, mean, kg & 0.11 & 0.17 & 0.16 & 0.06 & 0.03 & 0.18 & 0.09 \\
\hline Force, mean, \% & 14 & 22 & 19 & 8 & 4 & 23 & 11 \\
\hline \multicolumn{8}{|l|}{ T. eutamias } \\
\hline Mass, mean, $g$ & 0.08 & 0.08 & 0.05 & 0.03 & 0.01 & 0.08 & 0.04 \\
\hline Mass, mean, \% & 22 & 22 & 14 & 8 & 3 & 22 & 11 \\
\hline PCS, mean, $\mathrm{cm}^{2}$ & 0.14 & 0.13 & 0.12 & 0.05 & 0.04 & 0.11 & 0.11 \\
\hline Force, mean, kg & 0.36 & 0.33 & 0.29 & 0.14 & 0.10 & 0.28 & 0.28 \\
\hline Force, mean, \% & 20 & 19 & 16 & 8 & 6 & 16 & 16 \\
\hline \multicolumn{8}{|l|}{ C. cynomys } \\
\hline Mass, mean, $\mathrm{g}$ & 1.92 & 0.90 & 0.73 & 0.25 & 0.16 & 1.53 & 0.72 \\
\hline Mass, mean, \% & 31 & 14 & 12 & 4 & 3 & 25 & 12 \\
\hline PCS, mean, $\mathrm{cm}^{2}$ & 1.38 & 0.60 & 0.60 & 0.25 & 0.19 & 1.18 & 1.22 \\
\hline Force, mean, kg & 3.44 & 1.49 & 1.51 & 0.61 & 0.46 & 2.96 & 3.05 \\
\hline Force, mean, \% & 25 & 11 & 11 & 5 & 3 & 22 & 23 \\
\hline
\end{tabular}


Fig. 4. Mean lines of action of the adductor muscles at $\mathrm{IO}$ and $30^{\circ}$ gape in A. rufa and $M$. monax. Lines above the horizontal axis are at $\mathrm{IO}$ and lines below the axis are at $30^{\circ}$ gape. The length of each arrow represents the relative magnitude of the force.

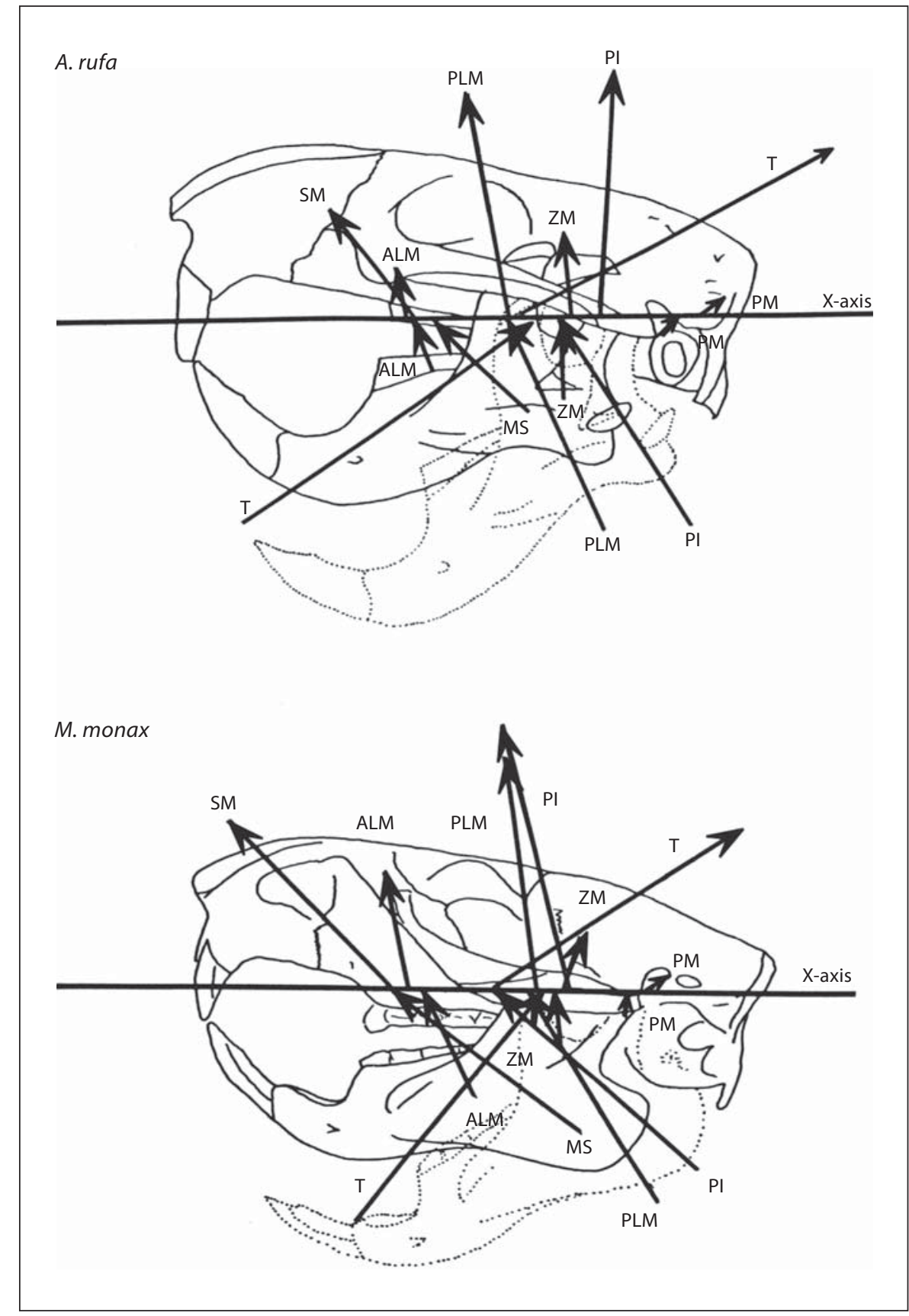

The ALM is a vertically oriented muscle with a small anterior component. The ALM has its greatest anterior component in Tamias, in which it makes an angle of $61.6^{\circ}$ to the horizontal at $30^{\circ}$ gape. The ALM has the longest MA of any of the adductor muscles. In all specimens, the MA of the ALM is longer at IO than at $30^{\circ}$ gape.

The orientation of the posterior lateral masseter (PLM) is similar to that of the ALM at IO, but in all seven species the mean orientation is directed more anteriorly than in 
the ALM at $30^{\circ}$ gape. In Marmota, Aplodontia, Cynomys, and Thomomys, mean MA lengths are significantly longer at IO than at $30^{\circ}$ gape. In each of the other three species (Tamias, Ratufa, and Sciurus) there is one specimen in which the MA of the PLM is longer at $30^{\circ}$ gape than at IO.

At IO, the line of action of the zygomaticomandibularis $(\mathrm{ZM})$ is directed slightly posteriorly in all species except Aplodontia, in which the mean is $87.9^{\circ}$. At $30^{\circ}$ gape, the mean line of action of the ZM is slightly anterior to the vertical in all species except Thomomys, in which the mean is $90.8^{\circ}$. The line of action of the posterior masseter is directed posteriorly in all seven species at both $\mathrm{IO}$ and $30^{\circ}$ gape. The line of action of the temporalis has a strong posterior component in all species at both IO and at $30^{\circ}$ gape. Clearly, the force produced by the temporalis is capable of producing very large changes in the direction of the bite force [DeMar and Barghusen, 1972; Throckmorton, 1985; Throckmorton and Throckmorton, 1985]. In an animal with a relatively large temporalis such as $A$. rufa, the large, posteriorly directed force produced by the temporalis shifts the line of action of the adductor muscle resultant posteriorly, producing a large angle between the direction of the bite force and the long axis of the lower incisor. Perhaps rodents are able to exert precise control over the direction of the bite force by changing the relative force exerted by the temporalis during biting.

The line of action of the PI is essentially vertical at IO and has a strong anterior component at $30^{\circ}$ gape. In some individuals of all species studied, the line of action of the most posterior fibers of the PI runs behind the craniomandibular joint (CMJ), so that these fibers would tend to open rather than close the jaw. Similar fibers have been reported in a hystricomorph (Cavia porcellus) [Chen and Herring, 1986].

\section{Adductor Muscle Resultants}

In general, the line of action of the total resultant of muscle forces is close to the vertical at IO and anteriorly directed at a gape of $30^{\circ}$ (fig. 5). In all species except Marmota and Tamias, the mean angle to the horizontal is actually greater than $90^{\circ}$ (the resultant is directed posteriorly), the greatest mean angle occurring in Aplodontia, in which the angle is $103.5^{\circ}$. The most anteriorly directed resultant at IO is in Tamias, in which the resultant makes an angle of $81.5^{\circ}$ to the horizontal. At $30^{\circ}$ gape, the mean resultants are all directed anteriorly. At $30^{\circ}$ gape, the most vertical resultant is in Aplodontia, in which the mean angle is $88.7^{\circ}$ to the horizontal, and the most ante-

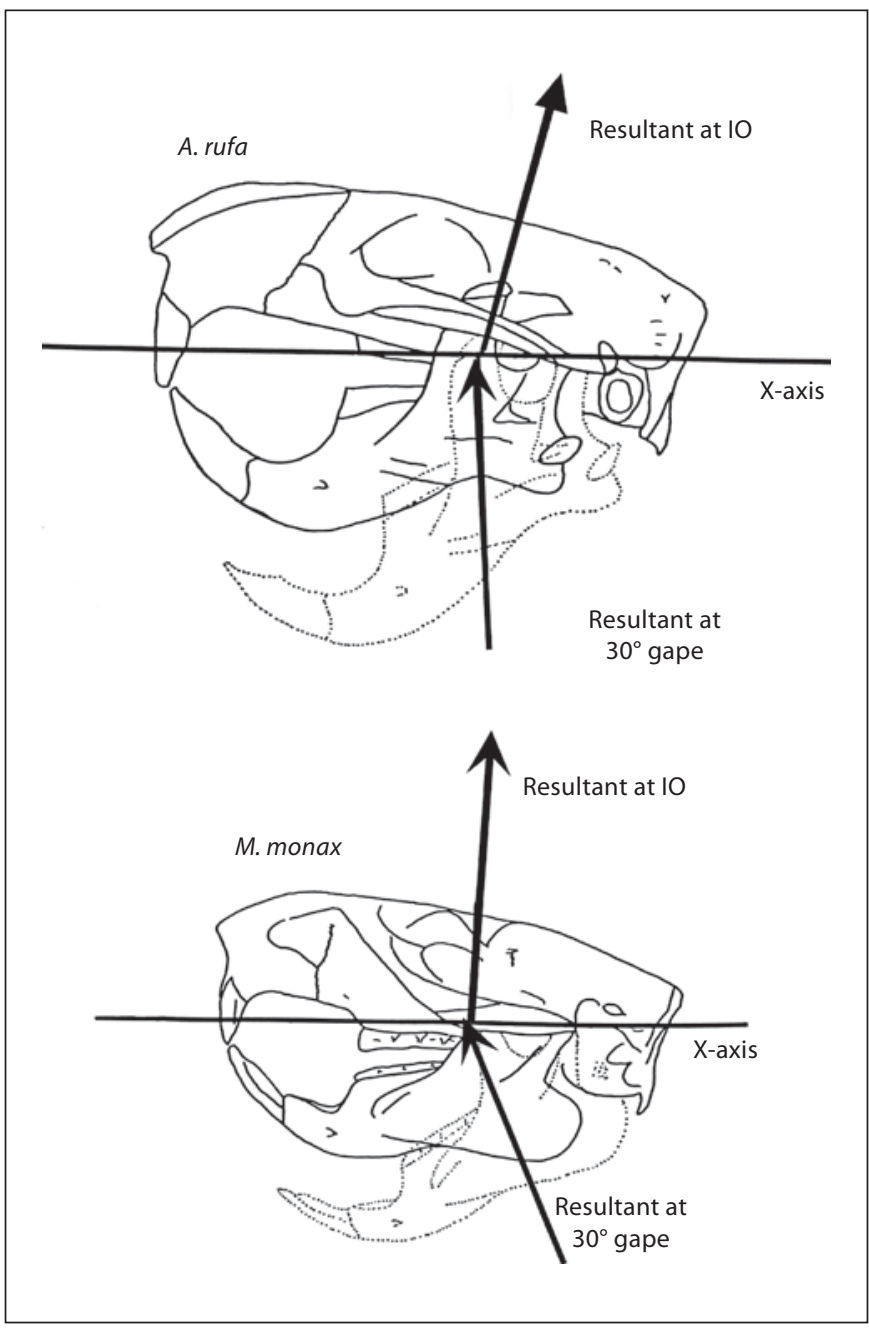

Fig. 5. Mean lines of action of the total resultant of adductor muscle forces at $\mathrm{IO}$ and at $30^{\circ}$ gape in A. rufa and M. monax. Lines above the horizontal axis are at IO and lines below the axis are at $30^{\circ}$ gape. The length of each arrow represents the relative magnitude of the force.

riorly directed resultant is found in Thomomys, in which the angle is $83.4^{\circ}$ to the horizontal. Mean actual MA lengths of the muscle resultants at IO range from $26 \%$ of jaw length in Aplodontia to $35 \%$ in Ratufa. At $30^{\circ}$ gape, MA lengths range from $26 \%$ of jaw length in Thomomys to $36 \%$ in Ratufa.

\section{Bite Forces}

At IO, mean estimated bite forces range from $14.78 \mathrm{~kg}$ in Marmota to $0.25 \mathrm{~kg}$ in Sciurus. At $30^{\circ}$ gape, forces range from $19.22 \mathrm{~kg}$ in Marmota to $0.23 \mathrm{~kg}$ in Sciurus. In all specimens of Marmota, Ratufa, Tamias and Cynomys, the bite force is greater at $30^{\circ}$ gape than at IO. 


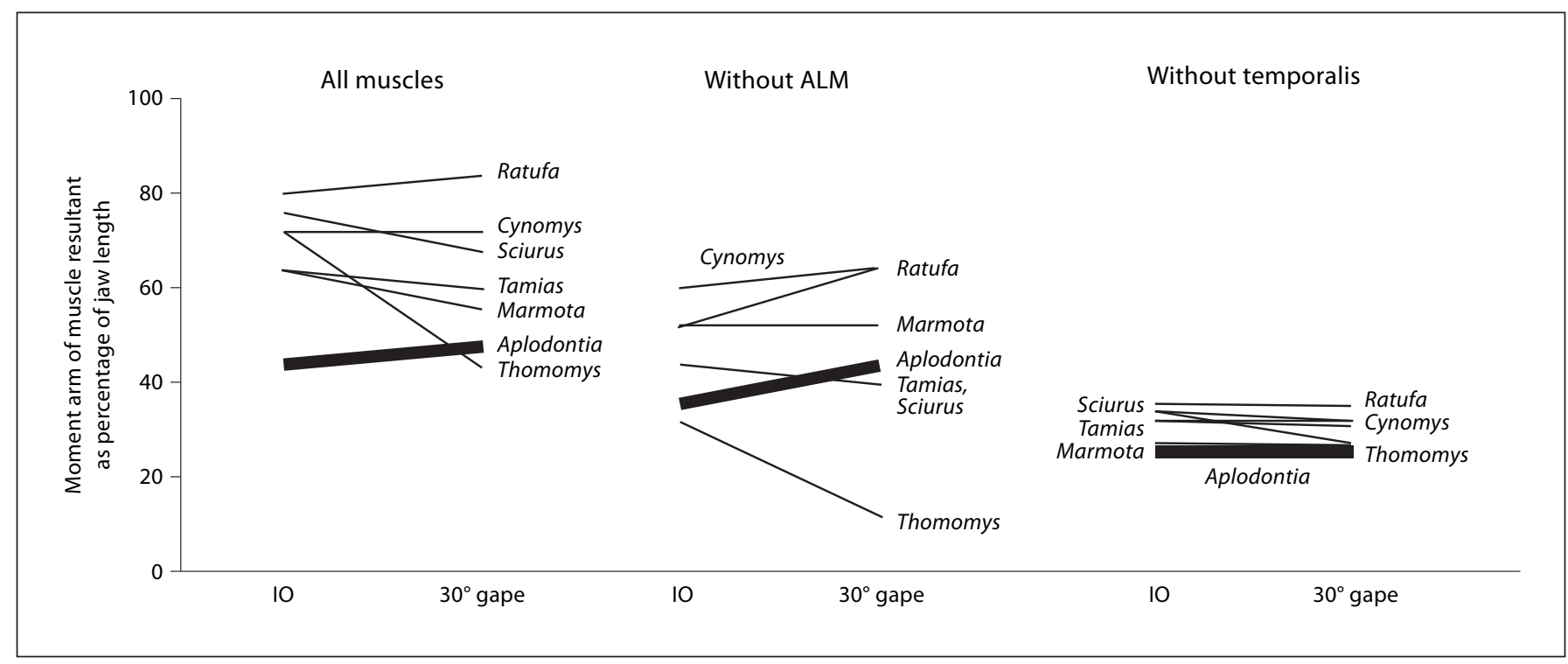

Fig. 6. Mechanical advantage of the resultant of adductor muscle forces at IO and at $30^{\circ}$ gape. The mean length of the MA of the resultant (as a percentage of total jaw length) for each species is given at IO and at $30^{\circ}$ gape. Left, resultants are calculated with all adductor muscles included. Middle, resultants are calculated with the ALM removed. Right, resultants are calculated with the temporalis muscles removed. Results for A. rufa are highlighted with a heavy black line.

\section{Discussion}

\section{Is the Mechanical Advantage of the Resultant of} Adductor Muscle Forces Greater in Sciuromorphs than in A. rufa?

One way in which the sciuromorph masticatory apparatus might be more efficient for incisal biting than that of $A$. rufa is that the mechanical advantage (the relative length of the MA) of the resultant of adductor muscle forces might be greater in sciuroids than in A. rufa. Comparisons of mechanical advantage in the 7 species are presented in figure 6 . At both $\mathrm{IO}$ and gapes of $30^{\circ}$, there is a nonrandom distribution of mean values for the 7 species (KW d.f. 6, IO 24.64, p < 0.001, 30 21.59, p = 0.001). At both gapes, the relative mechanical advantage in A. rufa is lower than in any of the sciuroids, although at $30^{\circ}$ gapes the nonsciuroid sciuromorph T. talpoides has a slightly lower mechanical advantage.

Since the major difference between the protrogomorph, $A$. rufa, and sciuromorphs is the relative size of the ALM, each of the mechanical comparisons are made with and without the ALM (KW d.f. 6, IO 29.64, p < $\left.0.001,30^{\circ} 29.24, \mathrm{p}<0.001\right)$. The utility of the ALM is clearly seen when the MA of the total resultant is calculated with and without the ALM (fig. 6). In A. rufa, in which the ALM represents only approximately $5 \%$ of the total PCS of the adductor muscles, the relative length of the MA is decreased only slightly. In the other species, the decreases are more dramatic. In T. talpoides, in which the ALM accounts for $32 \%$ of the total PCS of the adductor muscles, the relative length of the MA of the resultant at IO drops from $33 \%$ of jaw length when the ALM is included to $23 \%$ of jaw length when the resultant is calculated with the ALM excluded.

Since the relative width of the skull and mandible differs among the 7 species, and since relative width may be correlated with the relative size of the temporalis muscle (e.g., the relatively widest species have the relatively largest temporalis muscles), the mechanical comparisons are also made with and without the temporalis to evaluate the effect of skull width on the mechanics of incisal biting. When the resultants of adductor muscle forces are compared in the 7 species (fig. 6) with and without the temporalis, once again mechanical advantage is lowest in A. rufa (KW d.f. 6, IO 29.56, $\mathrm{p}=0.001,30^{\circ} 23.45, \mathrm{p}=$ 0.001 ). Therefore, the mechanical advantage of the resultant of adductor muscle forces is greater in sciuroids than in A. rufa. Furthermore, the feature of the incisal biting apparatus of $A$. rufa, which is most prominently correlated with the relatively wide skull (i.e. a relatively large 
Fig. 7. Bite force as a percentage of the estimated total force produced by the jaw adductor muscles at $\mathrm{IO}$ and at $30^{\circ}$ gape. Left, bite forces calculated with all adductor muscles included. Middle, bite forces calculated with the ALM removed. Right, bite forces calculated with the temporalis muscles removed. Results for A. rufa are highlighted with a heavy black line.

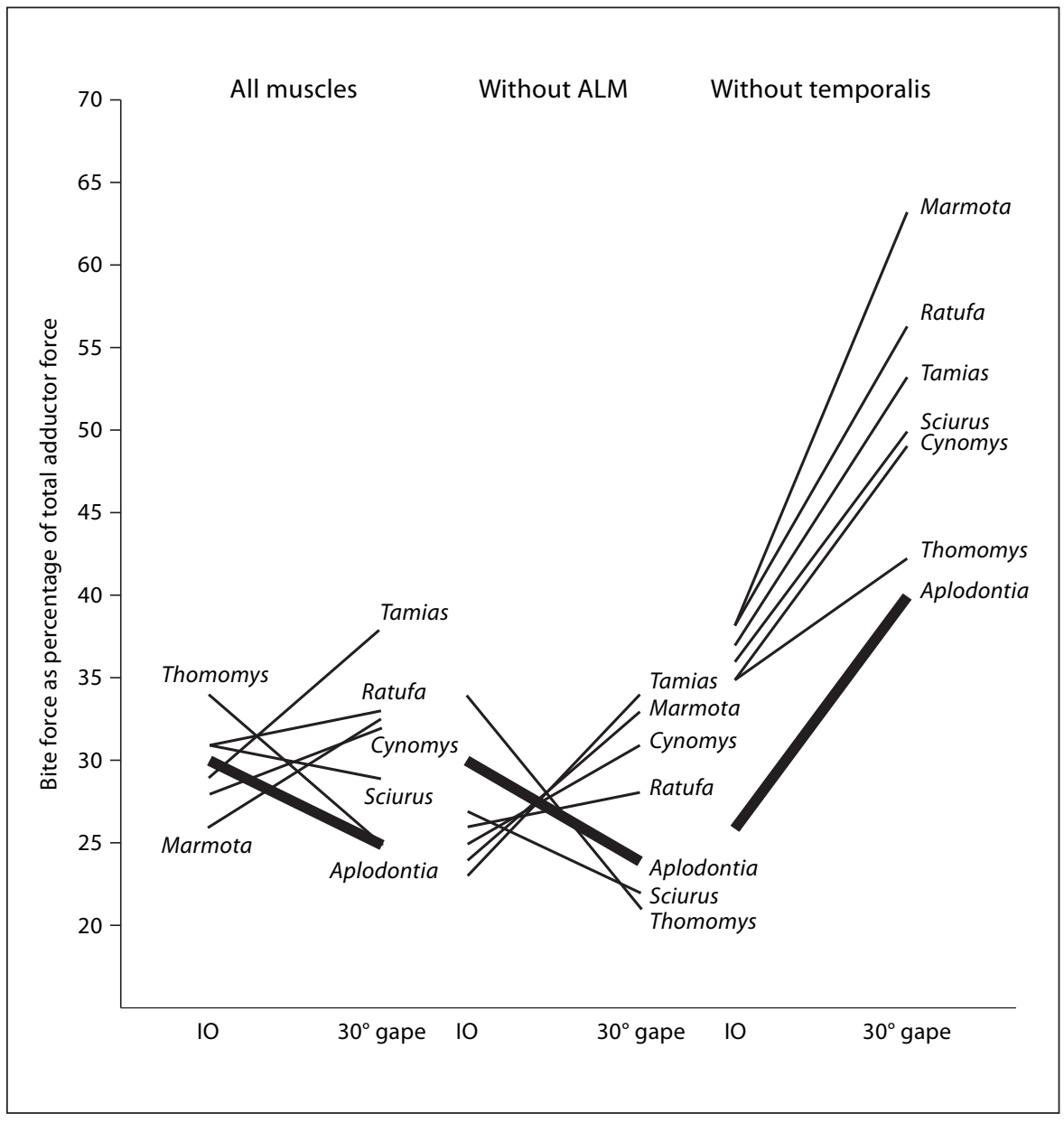

temporalis muscle), does not produce the low mechanical advantage of the adductor muscle resultant in A. rufa. The lower mechanical advantage of the masticatory muscles in $A$. rufa is due, at least in part, to the fact that $A$. rufa does not have large anterior sciuromorph extensions of muscle in front of the zygomatic arch.

\section{Is Relative Bite Force at the Incisors Greater in Sciuromorphs than in A. rufa?}

To compare relative force at the incisors, the estimated reaction force at the incisors is expressed as a percentage of the estimated total force produced by the jaw adductor musculature. Thus, for $\mathrm{N}$ units of force produced by the total cross-sectional area of the adductor musculature, $\mathrm{N}^{\prime}$ units of force are produced at the incisors, and relative bite force is equal to $\mathrm{N}^{\prime} / \mathrm{N}$, expressed as a percentage (KW d.f. 6 , IO 15.01, $\mathrm{p}=0.02,30^{\circ} 24.48, \mathrm{p}<0.001$ ). A similar procedure was employed by Baragar and Osborn [1987]. The results of the comparison of relative bite force are presented in figure 7. At IO, mean relative bite force in $A$. rufa is right in the middle of the values obtained for sciuroids, but at a gape of $30^{\circ} \mathrm{A}$. rufa has the lowest mean relative bite force.

When the ALM is removed from the calculations (fig. 7), the animals become slightly less efficient, but the effects are quite small (KW d.f. 6 , IO 18.66, $\mathrm{p}=0.05,30^{\circ}$ $17.24, p=0.08$ ). Although the decreases in efficiency are statistically significant, in all but one species at IO (Tamias) and one species at $30^{\circ}$ gape (Sciurus), the mean decrease is less than $5 \%$ (and the species are not significantly different from one another at $30^{\circ}$ gape). This suggests that although the ALM has a relatively long MA, its contribution to the efficiency of the masticatory apparatus is small. Even so, the effect of the ALM is clear (table 2). In A. rufa, in which the ALM represents approximately $5 \%$ of the total PCS of the adductor muscles, bite force estimated without the ALM is 96 and $99 \%$ (at IO and $30^{\circ}$ gape, respectively) of the total bite force estimat- 
Fig. 8. The percentage of the bite force projected along the long axis of the lower incisor at IO and at $30^{\circ}$ gapes. Left, bite forces calculated with all adductor muscles included. Middle, bite forces calculated with the ALM removed. Right, bite forces calculated with the temporalis muscles removed. Results for A. rufa are highlighted with a heavy black line.

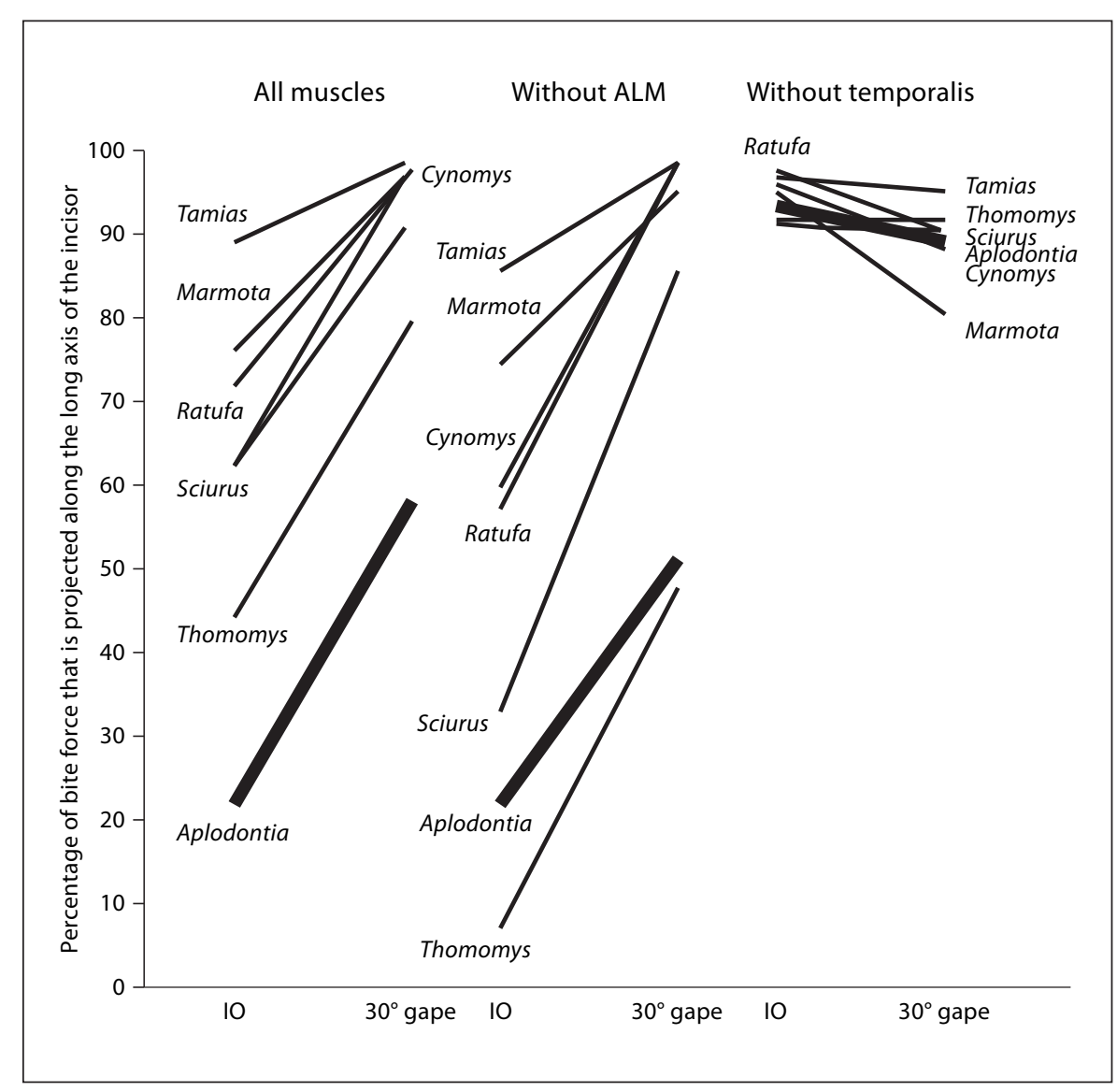

Table 2. Bite forces estimated without the ALM as a percentage of total bite force (means \pm SD)

\begin{tabular}{llll}
\hline Species & $\begin{array}{l}\text { Percent of } \\
\text { total muscle } \\
\text { force }\end{array}$ & $\begin{array}{l}\text { Percent of } \\
\text { bite force } \\
\text { at IO }\end{array}$ & $\begin{array}{l}\text { Percent of } \\
\text { bite force at } \\
30^{\circ} \text { gape }\end{array}$ \\
\hline M. monax $(\mathrm{n}=10)$ & 90 & $75 \pm 1$ & $83 \pm 2$ \\
A. rufa $(\mathrm{n}=9)$ & 95 & $96 \pm 2$ & $99 \pm 19$ \\
T. talpoides $(\mathrm{n}=10)$ & 68 & $68 \pm 9$ & $55 \pm 19$ \\
R. affinis $(\mathrm{n}=3)$ & 80 & $67 \pm 2$ & $70 \pm 2$ \\
S. variagatoides $(\mathrm{n}=3)$ & 78 & $69 \pm 7$ & $60 \pm 3$ \\
T. minimis $(\mathrm{n}=3)$ & 81 & $64 \pm 3$ & $75 \pm 1$ \\
C. ludovicianus $(\mathrm{n}=3)$ & 89 & $79 \pm 1$ & $86 \pm 2$ \\
\hline
\end{tabular}

ed with the ALM included (KW d.f. 6, IO 27.59, p < 0.001, $\left.30^{\circ} 29.87, \mathrm{p}<0.001\right)$. In the sciuromorphous species, the ALM represents a greater portion of the total PCS of the adductors and, as one would expect, the effect of removing the ALM is greater. For example, in Sciurus, in which the ALM is approximately $22 \%$ of the total PCS, bite force estimated without the ALM is only $69 \%$ of bite force estimated with the ALM included at IO and drops to $60 \%$ at $30^{\circ}$ gape. Thus, due to its advantageous position well forward on the jaw, the ALM does indeed account for a relatively large percentage of the bite force.

To assess the effects of skull width on the results, relative bite force is calculated without the temporalis muscle (KW d.f. 6, IO 21.24, $\mathrm{p}=0.002,30^{\circ} 21.85, \mathrm{p}=0.001$ ). At both gapes, mean relative bite force is lowest in $A$. rufa. If calculation of forces without the temporalis muscle does remove the effects of skull width, then relative bite force at the incisors is clearly greater in sciuromorphs than in A. rufa at $\mathrm{IO}$ and at $30^{\circ}$ gapes.

\section{Is the Percentage of Bite Force Projected Along the}

Incisor Axis Greater in Sciuromorphs than in A. rufa?

A third way in which the efficiency of the sciuromorphous masticatory apparatus might be greater than that of $A$. rufa is that sciuroids might be better than A. rufa at producing forces which would drive the lower incisors into an object being bitten. Let us assume that for the in- 
cisors to penetrate an object effectively, bite forces must be produced along the long axis of the incisor [Paphangkorakit and Osborn, 2008]. The angle between the long axis of the lower incisor and the direction of the bite force is measured (fig. 3), and the cosine of the angle, expressed as a percentage, gives the percentage of force projected along the long axis of the incisor. A similar measure is used by Osborn et al. [1986].

The mean percentage of force projected along the long axis of the lower incisor is given for each of the seven species in figure 8 . The distribution of means is nonrandom at IO and at $30^{\circ}$ gapes (KW d.f. 6, IO 24.54, p <0.001, 30 $20.56, \mathrm{p}=0.002)$. Percentages of force along the incisor are much lower in A. rufa than in any of the other species. These animals, particularly the sciurids, are quite good at producing force along the long axis of the lower incisor. At $30^{\circ}$ gapes, all of the sciurids put over $90 \%$ of the force along the axis of the incisor (the bite force makes an angle of less than $25^{\circ}$ with the incisor axis). Gambarian's [1960; cited in Hildebrand, 1985, pp. 100-101] observation that rodents with procumbent incisors tend to have anteriorly directed masticatory muscles may be correct. There does appear to be a relationship between the orientation of the bite force (which is, of course, dependent on the orientation of the muscle forces) and the orientation of the lower incisor.

Although the percentage of force along the incisor tends to be slightly lower when calculated without the ALM (fig. 8), the effect appears to be similar in most species (KW d.f. 6, IO 22.73, $\mathrm{p}=0.001,30^{\circ} 24.63, \mathrm{p}<0.001$ ). Among the aplodontoid-sciuroid species, the greatest decrease in efficiency occurs at IO in Sciurus, in which 62\% of the bite force is along the axis of the incisor with the ALM, but only $33 \%$ is along the incisor when the ALM is removed. In the geomyid Thomomys, the ALM represents $32 \%$ of the total PCS. When the ALM is removed from the calculations of bite force, it is not surprising that the direction of the force changes at IO and $30^{\circ}$ gape. At IO, $44 \%$ of the bite force is along the incisor when the ALM is included but only 7\% when the ALM is removed. At $30^{\circ}$ gape, $79 \%$ of the bite force is along the incisor when the ALM is included, but that drops to $48 \%$ when the ALM is removed.

To correct for skull width, forces are recalculated without the temporalis muscle (fig. 8). At IO, the distribution of mean values is not significantly different from random, but at $30^{\circ}$ gapes the distribution of means is nonrandom (KW d.f. 6 , IO 6.15, $\mathrm{p}=0.406,30^{\circ} 15.93, \mathrm{p}=$ 0.014). Without the temporalis muscle, force projected along the lower incisor in $A$. rufa is well within the mean values of the sciuroid species at both gapes.
Removal of the temporalis from calculations of bite force does, however, have a profound effect on the direction of the bite force. Without the temporalis, mean bite force directions are all within $25^{\circ}$ of the orientation of the lower incisor (except for M. monax at $30^{\circ}$ gapes, in which the mean angle between the bite force and the tooth axis is about $35^{\circ}$ ). When the temporalis is included in the calculations, angles between the bite force and the incisor axis are much larger. The mean angle in $A$. rufa at IO is approximately $78^{\circ}$ and only $22 \%$ of the force is projected along the long axis of the incisor.

If removal of the temporalis muscle from the calculations does correct for the effects of skull width (and, in a sense, brings all of the animals to the same width), then there is no difference in the percentage of force projected along the lower incisor in A. rufa and sciuroids. Unlike the first two measures, the arrangement of the adductor muscles of sciuroids is not more efficacious for the production of force at the incisors than that of $A$. rufa.

In conclusion, in two of the three hypotheses tested, the sciuromorphous masticatory apparatus is better able to produce forces at the incisors than the apparatus of $A$. rufa. If $A$. rufa does represent the primitive condition for the aplodontoid-sciuroid clade, than the derived sciuromorphous condition may, using these criteria, be considered an 'improvement' upon the primitive, protrogomorphous condition.

\section{Acknowledgement}

I would like to thank all of the many individuals who helped me in the course of this research. In particular, I would like to acknowledge the help of Walter Greaves, Sue Herring, the late Jim Fuller, and all of the other past and present members of the Departments of Oral Anatomy and Anatomy (now Oral Biology), University of Illinois at Chicago; Dean Dessem, Keith Condon, Rebecca German, and other fellow graduate students and postdocs; David DeCalesta and Gary Witmar at Oregon State University, and John Yunger at Governors State University. Special thanks to W.D. Carlock. This work would not have been possible without years of support from Renée, Rachael, and Leah. Thanks to L. Gallo and one anonymous reviewer for constructive comments. This study was supported in part by grants from Sigma Xi, the National Institute for Dental Research (R03 DE06279), and the University of Illinois at Chicago.

\section{Appendix 1}

The density of muscle is estimated as $1.0564 \mathrm{~g} / \mathrm{cm}$ [Mendez and Keys, 1960]. $\mathrm{k}$, the force produced by $1 \mathrm{~cm}^{2}$ of muscle, is estimated as $2.5 \mathrm{~kg} / \mathrm{cm}$, which is near the average of values measured by Muhl et al. [1978] in the digastric muscle of rabbits and close
60

Cells Tissues Organs 2010;192:50-63
Druzinsky 
to values obtained from postcranial muscles in other species [Spector et al., 1980; Powell et al., 1982; Roy et al., 1982]. The PCS is calculated as

$$
\operatorname{PCS}\left(\mathrm{m}^{2}\right)=\frac{\operatorname{Mass}(\mathrm{kg})}{\text { Fiber } \log (\mathrm{m}) \times \text { Density }\left(\frac{\mathrm{kg}}{\mathrm{m}^{3}}\right)}
$$

[after Bodine et al., 1982; Roy et al., 1984]. The force $(F)$ produced by a muscle is estimated by

$$
F(k g)=c\left(\frac{k g}{m^{2}}\right) \cos P \times P C S\left(m^{2}\right)
$$

[Fick, 1910; Gans and Bock, 1965], where $c$ is an estimate of the force produced by $1 \mathrm{~cm}^{2}$ of muscle and $P^{\prime}$ is the pinnation angle of the fibers in the muscle.

Pinnation angles were not measured in the present study, so a cosine equal to one (1.0) is used. In most of the adductor muscles, the pinnation angles are small, so their cosines are very close to 1.0. In the most complex muscles, the temporalis and medial pterygoid, the angles are large, so muscular forces are probably overestimated in these muscles. Since pinnation angles decrease as muscles lengthen [Benninghoff and Rollhauser, 1952] force $(F)$ is probably estimated more accurately at $30^{\circ}$ gape than at IO.

The moment (MOM) of a muscle is defined as the product of the force $(F)$ produced by the muscle and the length of the moment arm $(M A)$, which is defined as the perpendicular distance between the center of rotation (the joint) and the line of action, or

$M O M=F \times M A$

The articulation of the mandibular condyle within the CMJ is defined as the center of rotation (as well as the origin of the coordinate system), the horizontal axis (or X-axis) is defined as a line constructed between the joint and the cranial end of the wear facet on the upper incisor, and the vertical axis (or Y-axis) is an axis perpendicular to the horizontal axis, passing through the origin.

The force produced by each muscle can be divided into a horizontal component $\left(\mathrm{F}_{\mathrm{H}}\right)$ that acts along the horizontal axis and a vertical component $\left(\mathrm{F}_{\mathrm{V}}\right)$ that acts parallel to the vertical axis [Throckmorton, 1985; Throckmorton and Throckmorton, 1985]. The vertical components produce rotation around the joint and the horizontal components produce mandibular translation [Bock, 1968; Throckmorton and Throckmorton, 1985]. If the horizontal components of muscle force are considered to act along the horizontal axis, in the plane of the long axis of the CMJ, horizontal components of muscle force can only produce translatory movements of the lower jaw and therefore do not contribute to the turning moments around the joint, because there is no articular eminence.

The X-and Y-coordinates of the origins and insertions of each representative fiber of each muscle are recorded rather than estimating the length of the MA and orientation of each fiber directly. The orientation of each fiber is found by

$$
\alpha_{n}=\arctan \left(\frac{Y_{\text {ORIGIN }}-Y_{\text {INSERTION }}}{X_{\text {ORIGIN }}-X_{\text {INSERTION }}}\right)
$$

The moment $\left(M O M_{n}\right)$ produced by each representative fiber is found by finding the X-intercept of the line of action $\left(M A L_{n}\right)$

$$
\mathrm{MOM}_{n}=F_{n} \sin \alpha_{n} \times M A L_{n}
$$

and the moment arm $\left(M A_{n}\right)$ is also found using $M A L_{n}$, by substitution

$$
M A_{n}=M A L_{n} \sin \alpha_{n}
$$

so the determination of the length of the MAL for each muscle precedes the determination of the MA for each muscle.

Using the orientation and the force $\left(F_{n}\right)$, the moment arm $\left(M A_{n}\right)$, and the moment $\left(M O M_{n}\right)$ around the CMJ are determined for each of seven adductor muscles considered (SM, ALM, PLM, AZM, PZM, temporalis, PI) for each of the two gapes (IO and $30^{\circ}$ ) in each specimen. Static equilibrium conditions are assumed, so that

$$
\sum M O M=0, \quad \sum F_{V}=0, \quad \sum F_{H}=0
$$

Given $\mathrm{n}$ muscles, with forces $F_{1} \ldots F_{n}$, the calculation of moments and the resultant of muscle forces $\left(M U S C L E_{F}\right)$ is as follows: Vertical components of muscle forces are given by

$$
\begin{aligned}
& F_{V_{\mathrm{n}}}=F_{n} \sin \alpha_{n} \\
& \text { MUSCLE } F_{F_{V}}=\sum_{i=0}^{n} F_{V_{i}}
\end{aligned}
$$

horizontal components of muscle forces are given by

$$
\begin{aligned}
& F_{H_{\mathrm{n}}}=F_{n} \cos \alpha_{n} \\
& \text { MUSCLE } E_{F_{H}}=\sum_{i=0}^{n} F_{H_{i}}
\end{aligned}
$$

moments produced by the muscles are given by

$$
M U S C L E_{M O M}=\sum_{i=0}^{n} M_{i}
$$

If it is assumed that friction at the jaw joint is negligible so that the mandible is free to translate anteriorly and posteriorly, then horizontal components of muscle forces, even if they are not directed along the axis of the glenoid fossa, do not produce rotation around the jaw joint. Since horizontal components contribute only to translation of the jaw, moments around the CMJ produced by horizontal components of muscle forces equal 0 , so horizontal components of force are ignored when computing turning moments around the CMJ.

The magnitude of the total resultant of muscle forces is

$$
\operatorname{MUSCLE}_{F}=\left(\sum F_{V}\right)^{2}+\left(\sum F_{H}\right)^{2}
$$

and the orientation of the muscle resultant to the $\mathrm{X}$-axis is

$$
{ }^{\circ} \operatorname{MUSCLE}_{F}=\arctan \left(\frac{\sum F_{V}}{\sum F_{H}}\right)
$$

The bite force $\left(B I T E_{F}\right)$, or reaction force at the incisor, and the reaction force at the $\mathrm{CMJ}\left(C M \mathrm{~J}_{F}\right)$ are estimated by considering rotational moments around the bite point rather than the CMJ [Bramble, 1978]. This analysis rests on three assumptions:

(1) Static equilibrium conditions prevail,

(2) the CMJ resists only vertical forces, and

(3) the entire horizontal component of the muscle resultant is resisted at the bite point. 
The moment produced by the joint reaction force $\left(C M J_{M O M}\right)$ is equal and opposite to the moment produced by the adductor muscles (MUSCLE $E_{M O M}$ )

$$
M U S C L E_{M O M}=-C M J_{M O M}
$$

because the sum of moments is 0 ,

$$
0=\Sigma_{M O M}=M U S C L E_{M O M}+C M J_{M O M}
$$

The MA $\left(C M J_{M A}\right)$ of the joint reaction force $\left(C M J_{F}\right)$ about the bite point is the perpendicular distance between the CMJ and the bite point, and

$$
C M J_{M O M}=-M U S C L E_{M O M}=C M J_{F} \times C M J_{M A}
$$

so,

$$
C M J_{F}=-\frac{M U S C L E_{M O M}}{C M J_{M A}}
$$

The vertical component of the bite force $\left(B I T E F_{V}\right)$ is found by so,

$0=\Sigma \mathrm{F}_{V}=M U S C L E \mathrm{~F}_{V}+C M J_{F}+B I T E \mathrm{~F}_{V}$

$$
\begin{aligned}
& -M U S C L E \mathrm{~F}_{V}=C M J_{F}+B I T E F_{V} \\
& B_{T T E F_{V}}=M U S C L E F_{V}-C M J_{F}
\end{aligned}
$$

The horizontal component of the adductor muscle forces $\left(M U S C L E \mathrm{~F}_{H}\right)$ is resisted entirely by reaction forces at the bite point, so

$$
0=\Sigma \mathrm{F}_{H}=M U S C L E \mathrm{~F}_{H}+B I T E \mathrm{~F}_{H}
$$

and $M U S C L E \mathrm{~F}_{H}$ is equal and opposite to $B I T E \mathrm{~F}_{H}$

$$
B I T E F_{H}=-M U S C L E F_{H}
$$

The orientation of the bite force to the horizontal axis $\left(\theta_{\text {BITE }}\right)$ is found by

$$
\theta_{\text {BITE }}=\arctan \left(\frac{B I T E_{F_{V}}}{B I T E_{F_{H}}}\right)
$$

and the bite force $\left(B I T E_{F}\right)$ is given by

$$
B I T E_{F}=\sqrt{\left(B I T E_{F_{V}}\right)^{2}+\left(B I T E_{F_{H}}\right)^{2}}
$$

To estimate the orientation of the lower incisor relative to the horizontal axis, the following procedure is used:

For each skull measured, a photograph of the left mandible in lateral view was made. The horizontal axis is defined as a line passing through the tip of the incisor and the most superior point on the mandibular condyle (fig. 3). This line corresponds to the horizontal axis of the skull (as defined above) when the mandible is at $0^{\circ}$ gape or full occlusion of the upper and lower incisors. A line passing through the straightest portion of the wear facet on the lingual surface of the tooth is constructed, and used to represent the long axis of the lower incisor. The angle formed by the intersection of the horizontal axis and the long axis of the incisor is called angle ${ }{ }_{T о O т H}$ (fig. 3). At $\mathrm{X}^{\circ}$ gape, the orientation of the lower incisor is simply

$$
{ }^{{ }_{T O O O T H}}={ }^{\circ}{ }_{\text {TOOTH }}-\mathrm{x}^{0}
$$

The force produced along the long axis of the incisor $\left(\mathrm{TOOTH}_{F}\right)$, or normal to the cross-section of the incisor, is found by projection of the bite force vector $\left(B I T E_{F}\right)$ onto the long axis of the incisor using the cosine of the angle between the bite force and the long axis of the incisor (fig. 3):

$$
\text { TOOTH }_{F}=\text { BITE }_{F} \cos \left(\theta_{\text {BITE }}-{ }^{-} \text {TOOTH }_{X}\right)
$$

\section{References}

Ball, S.S., V.L. Roth (1995) Jaw muscles of New World squirrels. J Morphol 224: 265-291.

Baragar, F.A., J.W. Osborn (1987) Efficiency as a predictor of human jaw design in the sagittal plane. J Biomech 20: 447-457.

Bekele, A. (1983) The comparative functional morphology of some head muscles of the rodents Tachyoryctes splendens and Rattus rattus. I. Mammalia 47: 395-419.

Benninghoff, A., H. Rollhauser (1952) Zur inneren Mechanik des gefiederten Muskels. Pflügers Arch ges Physiol 254: 527-548.

Bock, W.J. (1968) Mechanics of one- and twojoint muscles. Am Mus Novit 2319: 1-45.

Bodine, S.C., R.R. Roy, D.A. Meadows, R.F. Zernicke, R.D. Sacks, M. Fournier, V.R. Edgerton (1982) Architectural, histochemical, and contractile characteristics of a unique biarticular muscle: the cat semitendinosus. J Neurophysiol 48: 192-201.

-Bramble, D.M. (1978) Origin of the mammalian feeding complex: models and mechanisms. Paleobiology 4: 271-301.
Cardini, A. (2003) The geometry of marmot (Rodentia: Sciuridae) mandible: phylogeny and patterns of morphological evolution. Syst Biol 52: 186-205.

Cardini, A., R.S. Hoffmann, R.W. Thorington, Jr. (2005) Morphological evolution in marmots (Rodentia, Sciuridae): size and shape of the dorsal and lateral surfaces of the cranium. J Zool Syst Evol Res 43: 258-268.

-Cardini, A., P. O'Higgins (2004) Patterns of morphological evolution in Marmota (Rodentia, Sciuridae): geometric morphometrics of the cranium in the context of marmot phylogeny, ecology and conservation. Biol J Linn Soc 82: 385-407.

Cardini A., P. Tongiorgi (2003) Yellow-bellied marmots 'in the shape space': sexual dimorphism, growth and allometry of the mandible. Zoomorphology 122: 11-23.

Chen, E., S.W. Herring (1986) An unusual function for the medial pterygoid muscle in the guinea pig. Arch Oral Biol 31: 781-783.

-DeMar, R., H.R. Barghusen (1972) Mechanics and the evolution of the synapsid jaw. J Evol 26: 622-637.
Druzinsky, R.E. (1981) Shapes of Dental Arcades in Primates; thesis. University of Illinois at the Circle, Chicago.

Druzinsky, R.E. (1989) Incisal biting in Aplodontia rufa and Marmota monax; Ph D thesis, University of Illinois, Chicago. Ann Arbor, University Microfilms International.

Druzinsky, R.E. (1995) Incisal biting in the mountain beaver (Aplodontia rufa) and woodchuck (Marmota monax). J Morphol 226: 79-101.

Druzinsky, R.E. (2010) Functional anatomy of incisal biting in Aplodontia rufa and sciuromorph rodents - Part 1: Masticatory muscles, skull shape, and digging. Cells Tissues Organs 191: 510-522.

English, A.W. (1985) Limbs vs jaws: can they be compared? J Am Zool 25: 351-363.

Gambarian, P.P. (1960) Adaptive characteristics of the locomotor organs in burrowing mammals (in Russian). J Akad Nauk Armianskoi SSR (Erevan). (Not seen, cited by Hildebrand, 1985). 
Gans, C., F. De Vree (1987) Functional bases of fiber length and angulation in muscle. J Morphol 192: 64-85.

- Hiiemae, K. (1971) The structure and function of the jaw muscles in the rat (Rattus norvegicus L.). III. The mechanics of the muscles. Zool J Linn Soc 50: 111-132.

Hildebrand, M. (1985) Digging of quadrupeds; in Hildebrand, E.M., D.M. Bramble, K.F. Liem, D.B. Wake (eds): Functional Vertebrate Morphology, Cambridge, The Belknap Press of Harvard University Press, pp 89109.

Mainland, D., J.E. Hiltz (1934) Forces exerted on the human mandible by the muscles of occlusion. J Dent Res 14: 107-123.

Mendez, J., A. Keys (1960) Density and composition of mammalian muscle. J Metabol 9: 184-188.

Muhl, Z.F., A.F. Grimm, P.L. Glick (1978) Physiologic and histologic measurements of the rabbit digastric muscle. J Archs Oral Biol 23: 1051-1059.

Osborn, J.W., F.A. Baragar, P.E. Grey (1986) The functional advantage of proclined incisors in man; In Russell, D.E., J.P. Santoro, D. Sigognean-Russell (eds): Teeth Revisited: Proc VII Int Symp Dental Morphology. Mém Mus Nat Hist Paris C, vol 53, pp 445-458.

Paphangkorakit, J., J.W. Osborn (2008) Proclination of lower incisors: a design to maximize food penetration and minimize torque. J Oral Rehab 35: 870-874.

Powell, P.L., R.R. Roy, P. Kanim, M. Bello, V.R. Edgerton (1982) Predictability of skeletal muscle tension output from architectural determinations (abstract). Physiologist 25: 259.
Roy, R.R., I.D. Meadows, K.M. Baldwin, V.R. Edgerton (1982) Functional significance of compensatory overloaded rat fast muscle. J Appl Physiol 52: 473-478.

Roy, R.R., P.L. Powell, P. Kanim, D.R. Simpson (1984) Architectural and histochemical analysis of the semitendinosus muscle in mice, rats, guinea pigs and rabbits. J Morphol 181: 155-160.

Satoh, K. (1997) Comparative functional morphology of mandibular forward movement during mastication of two murid rodents, Apodemus speciosus (Murinae) and Clethrionomys rufocanus (Arvicolinae). J Morphol 231: $131-142$.

Satoh, K. (1998) Balancing function of the masticatory muscles during incisal biting in two murid rodents, Apodemus speciosus and Clethrionomys rufocanus. J Morphol 236: 4956.

Satoh, K., Iwaku, F. (2004) Internal architecture, origin-insertion site, and mass of jaw muscles in Old World hamsters. J Morphol 260: 101-116.

Satoh, K., Iwaku, F. (2006) Jaw muscle functional anatomy in northern grasshopper mouse, Onychomys leucogaster, a carnivorous murid. J Morphol 267: 987-999.

Satoh, K., F. Iwaku (2008) Masticatory muscle architecture in a murine murid, Rattus rattus, and its functional significance. Mamm Study 33: 35-42.

Siegel, S. (1956) Nonparametric Statistics for the Behavioral Sciences. New York: McGrawHill.
Spector, S.A., P.F. Gardiner, R.F. Zernicke, R.R. Roy, V.R. Edgerton (1980) Muscle architecture and force-velocity characteristics of cat soleus and medial gastrocnemius: implications for motor control. J Neurophysiol 44: 951-960.

Stein, R.B. (2000) Morphology of subterranean rodents; in Lacey, E.A., J.L. Patton, G.N Cameron (eds): Life underground: the biology of subterranean rodents. Chicago, University of Chicago Press, pp 19-61.

Stern, J.T., Jr. (1974) Computer modelling of gross muscle dynamics. J Biomech 7: 411428.

Thorington, R.W., Jr., K. Darrow (1996) Jaw muscles of Old World squirrels. J Morphol 230: 145-165.

Throckmorton, G.S. (1985) Quantitative calculations of temporomandibular joint reaction forces. II. The importance of the direction of jaw muscle forces. J Biomech 18: 453-461.

Throckmorton, G.S., L.S. Throckmorton (1985) Quantitative calculations of temporomandibular joint reaction forces. I. The importance of the magnitude of the jaw muscle forces. J Biomech 18: 445-452.

Velhagen W.A., V.L. Roth (1997) Scaling of the mandible in squirrels. J Morphol 232: $107-$ 132.

Wood, A.E. (1937) The mammalian fauna of the White River Oligocene. 2. Rodentia. Trans Am Phil Soc New Ser 28: 155-269.

Wood, A.E. (1965) Grades and clades among rodents. Evolution 19: 115-130. 